\title{
DIDO E LUCRÉCIA, DE VIRGÍLIO A SHAKESPEARE
}

\author{
Philip Russell HaRdie
}

University of Cambridge

\begin{abstract}
Resumo. Neste artigo, eu investigo as ligações entre a versão virgiliana de Dido - mulher que comete suicídio por ter perdido a castidade e que, proferindo uma maldição ao morrer, leva por fim a sua cidade de Cartago à destruição nas guerras Púnicas - e Lucrécia - mulher cujo suicídio como prova de sua inocência depois de um estupro é evento de caráter fundador na história da cidade de Roma, que acarreta a expulsão dos reis e a instauração da República. Segue-se ao estudo detalhado da narrativa virgiliana, no qual sustento que a sombra de Lucrécia paira sobre a figura de Dido, uma série de abordagens posteriores na história da associação de Dido a Lucrécia, desde os Pais da Igreja até Shakespeare.
\end{abstract}

Palavras-chave. Virgílio, Ovídio, Shakespeare, Lucrécia, Dido.

Em Seu épico inacabado Africa, Petrarca encena um banquete norte-africano no qual o rei númida Sífax entretém Lélio, amigo íntimo de Cipião. Nessa reescritura do banquete virgiliano de Dido, um poeta sem nome canta a história da Líbia e fala da fundação e da construção de Cartago pela rainha Dido (Afr. 3.418-29). Petrarca, aqui e em outra ocasião, adota a versão da casta Dido, na qual a rainha cartaginesa suicida-se para escapar do casamento com um rei vizinho: "ueteris non immemor illa mariti, / morte pudicitiam redimit. sic urbis origo / oppetiit regina ferox" (Afr. 3.422-4). ${ }^{1} \mathrm{O}$ poeta dá sequência a isso com uma reflexão indignada acerca do dano que seria causado ao renome de Dido se alguém confiante demais em sua própria inteligência fosse difamar a rainha escrevendo sobre um caso amoroso ilícito - "quod credere non est". Petrarca alude maliciosamente à versão alternativa, redigida por um poeta que só nasceria mais de um século depois dos eventos narrados em Africa: "ueteris non immemor illa mariti" lembra-nos de uma fidelidade que é suplantada na Eneida pelo ressurgimento daquilo que Dido sentia por seu antigo marido: "agnosco

${ }^{1}$ Bibliografia sobre a casta Dido: Lord 1969; Pease, Timaeus FrGH IIIB, 624; Justino 18.4-6. 
ueteris vestigia flammae" (4.23). ${ }^{2}$ A Dido de Petrarca permanece fiel porque continua ferox, enquanto, na Eneida, Mercúrio, agindo a mando de Júpiter, levou os cartagineses a abandonar seus ferocia corda para receber os troianos com hospitalidade (Aen. 1.302-4).

Lélio responde à canção da história da Líbia com um relato da história romana, que alcança um primeiro clímax no final do livro III com a narrativa de quase cem linhas do estupro de Lucrécia (Afr. 3.684-774), seguida de uma breve narrativa da expulsão dos Tarquínios, de Bruto executando seus filhos e da morte de Bruto em combate (Afr. 3.768-802). No início do livro seguinte, antes que Lélio prossiga seu relato acerca de Cipião, Sífax comenta a singularidade da grandiosa natureza do destino romano, mas também observa a semelhança entre as histórias de Lucrécia e (da casta) Dido: "sentio praeterea quid femina uestra pudica / morte uelit: ne cunta sibi iam candida Dido / arroget" (Afr. 4.4-6).

Ao equiparar Dido e Lucrécia como exempla de mulheres castas que preferiram o suicídio à desonra, Sífax - e Petrarca - segue uma tradição que remonta aos pais da Igreja, em particular, aos insistentes apelos de Tertuliano e de Jerônimo para que as mulheres preservassem a virgindade ou não se casassem uma segunda vez. ${ }^{3}$

A clara separação das Didos, casta e não casta, e a associação da casta Dido (sozinha) a Lucrécia causam complicações. ${ }^{4}$ Um exemplo da narrativa de Petrarca acerca da morte de Lucrécia e suas consequências: quando Bruto jura pelos deuses e pelo sangue de Lucrécia que perseguirá a casa dos Tarquínios com ódio eterno, são atribuídas a ele palavras que ecoam não apenas a maldição de Bruto na versão que Tito Lívio apresenta da história, mas também a maldição contra os troianos da impudica Dido virgiliana, no momento de sua morte, no livro Iv da Eneida. Compare:

Quod flammis ferroque genus sobolemque domumque

regis et inuisum caput ac diadema superbum

nunc, posthac, semper, mihi dum lux ista manebit,

persequar eternis odiis.

(Afr. 3.744-7)

\footnotetext{
2 Cf. também 4.457-8: "de marmore templum / coniugis antiqui". Com immemor cf. 4.194: "regnorum immemores turpique cupidine captos".

${ }^{3}$ Lord 1969, Allen 1968. Lucrécia e Dido, ambas em uma lista de mulheres virtuosas em Eustache Deschamps.

${ }^{4}$ Klecker 2003, para mais exemplos da alusão à Dido de Virgílio na história de Lucrécia em Petrarca: Afr. 3.684, "Regius infami iuuenis precordia flamma / succensus uulnusque trahens male sanus acerbum", cf. Verg. A. 4.101, "ardet amans Dido traxitque per ossa furorem", e 4.2, "uulnus alit uenis et caeco carpitur igni"; Afr. 3.697, "quin obis", cf. Verg. A. 4.547, "quin morere"; Afr. 3.737, "tremuitque domus sub murmure tanto", cf. Verg. A. 4.668, "tecta fremunt".
} 
com

exoriare aliquis nostris ex ossibus ultor qui face Dardanios ferroque sequare colonos, nunc, olim, quocumque dabunt se tempore uires. (Aen. IV.625-7)

Há uma conexão mais profunda aqui, no sentido de que os juramentos - ou maldições - de ambos, de Bruto e da impudica Dido, são aitia de fundação de grandes eventos na história de Roma e Cartago. A vingança de Bruto é fundadora da República romana, ao passo que a maldição de Dido será a causa das guerras Púnicas e, portanto, a causa da destruição de Cartago. Petrarca associa explicitamente as mortes tanto de Dido quanto de Lucrécia a momentos fundadores de suas respectivas cidades. Em Petrarca, o poeta africano fornece um tipo de epitáfio para sua breve narrativa sobre Dido: "sic urbis origo / oppetiit regina ferox" (Afr. 3.423-4). Ela fundou a "nova cidade" (Afr. 3.420: "ex re nomen ei est", aludindo à suposta etimologia de Cartago) e agora morre. Lélio comenta os eventos desencadeados pela morte de Lucrécia: "regnorum hic finis. Post hec meliora sequuntur / tempora, et hinc nostri libertas incipit eui" (Afr. 3.773-4). A morte de Lucrécia leva diretamente ao nascimento da República romana.

Neste artigo, eu investigo mais a fundo os laços entre Lucrécia e a Dido impudica, a Dido dos livros I e Iv da Eneida. Analiso os laços entre histórias de violação e fundação, refundação e o saque - ou "des-fundação" - de cidades e o papel da fama nessas histórias. Vou usar algum tempo expondo as conexões na narrativa virgiliana, sugerindo como uma forte hipótese, embora talvez insustentável, que a formatação que Virgílio dá à sua versão de Dido, qualquer que seja sua relação com a Dido de Névio, faz dela uma anti-Lucrécia nas histórias tanto de Cartago como de Roma. No final do artigo, analisarei uma série de textos clássicos e posteriores, nos quais a "contaminação" entre a Dido impudica ou virgiliana e Lucrécia se manifesta de várias maneiras.

Interessei-me pelas conexões entre Dido e Lucrécia quando trabalhava no meu livro sobre a história da fama - Rumour and Renown. ${ }^{5}$ Refleti sobre o fato de que fama e pudor são cruciais nas histórias de ambas as mulheres. A pudicitia - pudicícia, virtude sexual - de uma mulher está inextrincavelmente ligada a seu pudor - pudor, sentimento de vergonha - e a sua fama - reputação, bom nome. A Dido de Virgílio, acirradamente leal ao falecido marido, de início roga para ser atingida por um raio antes de violar seu pudor

${ }_{5}^{5}$ N.T.: Rumour and Renown: Representations of Fama in Western Literature foi publicado em 2012 pela Cambridge University Press, na série Cambridge Classical Studies. 
(A. 4.25-7) até que sua irmã Ana encontra as palavras certas para esvaziar esse pudor (Aen. 4.55). A união com Eneias na caverna é o momento em que Dido deixa de pensar em sua fama: "neque enim specie famaue mouetur" (Aen. 4.170). Mas quando descobre que Eneias pretende deixar Cartago, ela se conscientiza totalmente da perda de seu pudor e de sua fama: "te propter eundem / exstinctus pudor et, qua sola sidera adibam, fama prior" (Aen. 4.321-3). Essas linhas poderiam ainda ser lidas metapoeticamente, como um comentário do impacto da história de Virgílio acerca de Dido e Eneias sobre sua versão anterior ou tradição (fama, nesse sentido), na qual a conduta de Dido era ditada inabalavelmente por seu senso de pudor. A Lucrécia de Tito Lívio mata-se para provar que sua mente é inocente embora seu corpo tenha sido violado e, assim, continuar a viver não deveria se tornar um exemplum a ser seguido por outras impudicae: "nec ulla deinde impudica Lucretiae exemplo uiuet" ("nenhuma mulher impudica de agora em diante continuará a viver por causa do exemplo de Lucrécia", Liv. 1.58.10). Doravante, sua fama será inatacável como exemplo de virtude de mulher casada. Com sua morte, ela assume o controle do "muliebris certaminis laus" ("louvor atribuído numa disputa entre mulheres", Liv. 1.57.9), que era, sem que ela soubesse, seu prêmio na disputa entre as esposas, oferecido pelos maridos reunidos à mesa de Sexto Tarquínio. A frase muliebris certaminis laus sugere uma versão feminina do certamen gloriae, no qual homens romanos da aristocracia competiam para aumentar sua reputação e sua fama. Na versão de Ovídio dessa história, no livro iı dos Fasti, fama é a arma com a qual Tarquínio finalmente vence Lucrécia: "'falsus adulterii testis adulter ero: / interimam famulum, cum quo deprensa fereris.' / succubuit famae uicta puella metu" (Fast. 2.80710). A ênfase na fama, renome, vergonha, honra, é ainda mais pronunciada em alguns dos relatos posteriores acerca de Lucrécia, nada que se compare ao longo poema narrativo de Shakespeare, The Rape of Lucrece, ao qual voltarei no final do meu artigo.

Como já foi observado várias vezes, a violação sexual é intimamente associada às fundações de Roma em muitas histórias: ${ }^{6}$ o estupro de Reia Sílvia por Marte, concebendo o fundador de Roma, Rômulo; o rapto das sabinas, necessário para a existência de uma nova geração de romanos após a fundação da cidade; e a violação de Lucrécia, a oportunidade para a fundação da República. A violação cometida por um deus é uma fórmula para suprir uma família ou um Estado de um fundador semidivino e heroico, e os deuses não devem prestar contas de suas aventuras sexuais. O rapto das sabinas passa a ser aceitável quando as vítimas se tornam esposas. No

${ }^{6}$ Ver Joshel 2009, 381: "The rape of women becomes the history of the state"; Joplin 1990, Jed 1989. 
entanto, em geral, na sociedade patriarcal romana, resguardar o pudor e a fama femininos é essencial para a estabilidade da ordem familiar e social, e, portanto, uma condição para a propagação da fama de masculinidade e vigor, por meio das façanhas dos fundadores e líderes da cidade. No caso de Lucrécia, Sexto Tarquínio não é um deus, e sua vítima nunca poderá tornar-se sua esposa. A agressão pessoal cometida pelo filho do tirano contra o corpo e a reputação de Lucrécia é uma metonímia para a agressão do tirano contra as estruturas políticas e morais da cidade como um todo - a confusão do público e do privado é uma característica definidora da imagem de um tirano na Antiguidade.7 Somente pela violência contra seu próprio corpo, Lucrécia pode proteger seu pudor e sua fama de quaisquer questionamentos; paradoxalmente, a violação e penetração do seu próprio corpo com a espada tem o efeito de torná-la íntegra de novo na morte. Sua morte tem como consequência um ato de vingança masculina contra os tiranos que torna íntegro o corpo político por meio da fundação da República romana. Olhando de outro ângulo, o mau líder, o tirano, destrói "sua" cidade ou seu regime por meio do "saque" do corpo da mulher, o que prova ser, na verdade, um golpe autoinfligido contra seu próprio poder masculino e sua fama. Petrarca inicia sua narrativa da violação de Lucrécia fazendo referência à infamia que Sexto Tarquínio provoca por ser incapaz de controlar o próprio desejo: "Regius infami iuuenis precordia flamma / succensus" (Afr. 3.684-5). A linguagem alude ao fogo do amor de Dido (ver n.4), que vai levá-la a perder sua fama. Com essa perda da fama vem o fracasso de Dido em preservar o papel masculino de líder de seu povo e governante da própria cidade, um papel que lhe foi atribuído quando fugiu de Tiro: $d u x$ femina facti, como Vênus surpreendentemente coloca na Eneida 1.364 - dux é uma palavra costumeiramente aplicada aos homens. Ao defender sua fama com o suicídio, Lucrécia evidencia uma determinação que não é feminina. Valério Máximo a apresenta como $d u x,{ }_{,}^{8}$ e como sendo uma alma de homem em corpo de mulher: "Dux Romanae pudicitiae Lucretia, cuius uirilis animus maligno errore Fortunae muliebre corpus sortitus est" (Val. Max. 6.1). O famoso ato da mulher Lucrécia é o sine qua non para as ações dos homens: a famosa expulsão do tirano e a fundação da República romana.

Dido, na versão de Virgílio, por meio da sua fidelidade ao falecido marido Siqueu, ardilosamente morto pelo irmão dela, Pigmalião, rei de Tiro, consegue fundar a nova cidade de Cartago. Na versão da casta Dido, o suicídio dela para manter a fidelidade ao primeiro marido e evitar uma união in- 
desejada com um príncipe africano poderia ser vista como uma defesa bem sucedida da independência da sua cidade recentemente fundada e uma garantia contra a sua incorporação por outro reino. A pudicícia de Dido, como a de Lucrécia, é essencial para o bem-estar e até mesmo para a existência da sua própria cidade. Na versão de Virgílio, por meio da sincronização das histórias de Eneias e Dido, a fundação e o futuro sucesso ou fracasso de Cartago estão atrelados à futura fundação e história de outra cidade, Roma. A união de Dido a Eneias é uma ameaça não apenas à independência de uma comunidade governada pelo exilado troiano, mas à possibilidade mesma de fundação da cidade de Roma pelos descendentes de Eneias. A morte de Dido, um tipo de resgate, aos olhos dela, de sua fama e seu pudor, não leva à refundação de sua própria cidade, mas aniquila por completo uma relação que poderia ter se interposto à fundação de Roma. Com seu suicídio, ela encena um "casamento-funeral" que inviabiliza uma nova geração.

No livro Death in Ancient Rome, Catherine Edwards alerta para os paralelos "extremamente significativos" entre as mortes de Dido e Lucrécia, sendo que as duas cometem suicídio como redenção de culpa sexual e para vingar uma transgressão sexual:

Ao mesmo tempo, as mortes de ambas, Lucrécia e Dido, podem ser lidas como sacrifícios necessários à fundação e ao desenvolvimento adequado de Roma. A morte de Lucrécia é [...] um momento-chave na fundação da República romana. Sua morte é vingada por Bruto - que coloca o corpo dela em exposição para suscitar nos concidadãos sentimentos contrários ao governo injusto dos Tarquínios. Por outro lado, a morte de Dido pode ser encarada como necessária à fundação do Estado protorromano que é o destino de Eneias. ${ }^{10}$

"Esses três suicídios [Lucrécia, Dido, Cleópatra] assinalam três momentos-chave na história romana - ou protorromana" (Edwards 2007, 186), isto é, a fundação da comunidade protorromana, da República romana, do Principado de Augusto. Eu avanço em relação a Edwards, primeiramente, identificando um leque mais amplo de analogias entre Lucrécia e Dido. Em segundo lugar, ao enfatizar o tema do saque, da "des-fundação" de uma cidade, tanto quanto da fundação.

Volto a olhar com mais detalhe a equivalência entre o corpo feminino e a cidade. Como vimos, a agressão de Sexto Tarquínio ao corpo de Lucrécia é uma agressão figurada à cidade de Roma. ${ }^{11}$ Tito Lívio usa imagens militares na violação: "Quo terrore cum uicisset obstinatam pudicitiam uelut ui uic-

9 Verg. A. 4.495-7: "arma uiri thalamo quae fixa reliquit / impius exuuiasque omnis lectumque iugalem, / quo perii, super imponas". Ver Nelis 2001, 169-72; Moorton 1990.

${ }^{10}$ Edwards 2007, 184.

${ }^{11}$ Ver e.g. Donaldson 1982, 9: "Lucrécia é ... a figura da Roma violada". 
trix libido, profectusque inde Tarquinius ferox expugnato decore muliebri esset" (Liv. 1.58.5). Ele "atacou" a castidade de Lucrécia. Mas o jogo vai virar e a Roma dos Tarquínios é que será atacada para possibilitar o surgimento de uma Roma melhor e livre: "Brutum iam inde ad expugnandum regnum uocantem sequuntur ducem" (Liv.1.59.2). Na versão de Ovídio, Tarquínio, o Soberbo é apresentado como um tipo de anti-Eneias, um uir que usa arma para fins injustos, um saqueador de cidades, não um fundador de cidades: "ultima Tarquinius Romanae gentis habebat / regna, uir iniustus, fortis ad arma tamen. / ceperat hic alias, alias euerterat urbes" (Fast. 2.687-9). ${ }^{12}$ Seu filho mais jovem, Sexto, provou ser seu filho ao conquistar de maneira ardilosa a confiança da cidade de Gábios com o objetivo de capturá-la, de uma forma que alude à maneira traiçoeira com que Sínon persuadiu os troianos a introduzir na cidade o cavalo de madeira, no livro II da Eneida..$^{13}$ Sexto incita-se à violação de Lucrécia ao se recordar de seu êxito na conquista de Gábios: "cepimus audendo Gabios quoque" (Fast. 2.783). A analogia entre o saque da cidade e a violação pode ir ainda mais longe. Quando Ovídio narra como Tarquínio cortou as flores mais compridas como uma mensagem secreta ao seu filho para que matasse os líderes de Gábios, as papoulas que aparecem em todas as outras versões da história são substituídas por lírios. Já foi sugerido que lírios evocam pureza e inocência e são por vezes associados a personagens antes de serem violentados: os inocentes líderes de Gábios prefiguram a inocente Lucrécia, vítimas todos de engodo por parte dos Tarquínios. ${ }^{14}$

A identificação do corpo de Dido com o corpo de sua cidade é de maior alcance. Repetindo a simetria imagética entre a morte de Príamo e a queda da cidade de Troia no livro II da Eneida, a morte de Dido no livro IV implica, de maneira figurada, a destruição de Cartago, desenvolvida no símile que compara o lamento pela morte dela ao lamento que decorreria da queda de Tiro ou de Cartago. Como é de conhecimento geral, esse símile é moldado no símile da Ilíada (22.410-11), comparando o lamento pela morte de Heitor ao lamento que decorreria da destruição de Troia - e que vai ocor-

${ }^{12}$ Confronte com Verg. A. 1.544-5: "rex erat Aeneas nobis, quo iustior alter / nec pietate fuit, nec bello maior et armis". Ovídio assume o rei(nado), a oposição entre guerra e paz, a referência a (in) justiça e ainda alude a "arma uirumque". Com "Romanae gentis", cf. Verg. A. 1.33: "tantae molis erat Romanam condere gentem".

${ }^{13}$ Cp. Sínon e Tarquínio na edição de Paulo Marso dos Fasti; a propos da entrada traiçoeira de Tarquínio na cidade de Gábios (Fast. II.689ss), veja Burrow 2002, 48-9. Os paralelos textuais: Ov. Fast. 2.693-4 ("occidite ... inermem! / hoc cupiant frater Tarquiniusque pater"), Verg. A. 2.103-4 ("iamdudum sumite poenas: / hoc Ithacus uelit et magno mercentur Atridae"); Fast. 2.699 ("flent quoque" - o povo de Gábios em reação à história de Tarquínio), Verg. A. 2.145 ("his lacrimis uitam damus et miserescimus ultro"). Ver Robinson 2011, sobre Fast. 2.689-710. Phillipides (1983, 113) identifica um paralelojá no texto de Tito Lívio entre o cerco de Tarquínio, o pai, a Árdea, motivado pela superbia e a necessidade de dinheiro, e a tomada de Lucrécia por Sexto, motivada pelo desejo sexual.

${ }_{14}$ Felton 1998, 49-50, citado por Robinson 2011, sobre Ov. Fast. 2.706. 
rer, num futuro não tão distante, como consequência direta da morte do defensor de Troia, Heitor. O saque de Cartago em um futuro distante será o efeito da maldição de Dido ao morrer, quando clama pela inimizade perpétua entre Roma e Cartago e conclama o vingador Aníbal. ${ }^{15}$ A vingança de Bruto motivada pela morte de Lucrécia resulta na fundação da República romana; a vingança contra Roma invocada por Dido ao morrer vai resultar na destruição de sua própria cidade. ${ }^{16}$ Ana, a irmã de Dido, inadvertidamente também profetiza a destruição de Cartago ao exacerbar o luto, equiparando a morte de Dido à morte de seu povo e de sua cidade: "exstinxti te meque, soror, populumque patresque/Sidonios urbemque tuam" ( $A$. 4.682-3). A morte de Dido é necessária para a futura fundação de Roma e é também a causa principal da destruição de Cartago. A fundação de Roma é consequência da queda de Troia. Cartago será destruída numa repetição da queda de Troia: isso decorre da retomada do símile da morte de Heitor no canto 22 da Ilíada. A história da destruição de sua cidade, que Eneias conta à mesa de jantar de Dido e que alimenta a simpatia dela e seu amor pelo forasteiro, é também a história do que acontecerá à nova cidade de Dido, literalmente, num futuro distante e, antecipadamente de maneira figurada, no momento de sua morte, num futuro próximo.

O próprio Eneias já foi considerado um cavalo de Troia dentro dos muros de Cartago ou um Sínon, um suposto amigo que traz destruição. Eneias é o agente (involuntário) do ardil de Vênus para atacar a "cidadela" da fama e o corpo de Dido: "quocirca capere ante dolis et cingere flamma / reginam meditor" (Verg. A. 1.673-4). ${ }^{17}$ Há uma ironia cruel em impingir o papel de saqueador de cidades ao fundador de cidades Eneias, mas é uma crueldade que é bondade do ponto de vista do futuro da cidade de Roma. A fama que realmente importa nessa história é a "famamque et fata nepotum" (Verg. A. 8.731), a gloriosa futura história de Roma, como é representada no escudo de Eneias e revelada no desfile dos heróis, não a fama e o pudor da rainha Dido. Talvez seja essa uma razão por que Virgílio é tão ferino com a fama de Dido em seu poema.

O fato de a queda de Troia funcionar como ponto de partida da trajetória narrativa rumo à fundação de Roma e como parada final em direção à qual avança a história de Cartago é apenas um exemplo da relação espe-

${ }^{15}$ Cf. com a maldição de Dido, o juramento de Bruto em Tito Lívio 1.59.1: “. . . me L. Tarquinium Superbum cum scelerata coniuge et omni liberorum stirpe ferro igni quacumque dehinc ui possim exsecuturum..."

${ }_{16}$ Vingança: Verg. A. 4.654-5 ("urbem praeclaram statui, mea moenia uidi, / ulta uirum poenas inimico a fratre recepi"); 4.659-60 ("moriemur inultae, / sed moriamur"). Isso, apesar de (ou por causa de ?) 4.625 ("exoriare aliquis nostris ex ossibus ultor").

${ }_{17}$ Sobre as imagens de tomada da cidade aqui e no livro 4, veja Lyne 1987, 18-20. 
cular que liga os enredos de Eneias e Dido, de Roma e Cartago, uma relação que se inicia com a geminação direta das histórias dos exilados de Troia e de Tiro e que é, então, invertida num espelhamento negativo. De saída, Dido é um alter Aeneas, tendo perdido o esposo e sendo forçada a assumir o papel de líder de um grupo de concidadãos no exílio com a missão de fundar uma cidade. Quando encontra o verdadeiro Eneias, ela deixa de desempenhar um papel masculino para assumir o papel de Lucrécia, que ela já tinha desempenhado na outra versão de sua própria história, mas agora como anti-Lucrécia, cuja morte não leva à nova fundação da sua cidade, mas abre passagem para a fundação de outra cidade e dá início a uma série de acontecimentos que vão levar à destruição de sua própria cidade.

A sombra de Lucrécia é uma das causas da complexidade de nossas reações à Dido de Virgílio. Embora ela sofra uma derrocada à qual Lucrécia, pelo menos na visão mais disseminada, está imune, Dido retoma na morte algo de seu orgulho, de sua fama, até mesmo de sua pudicitia. Dido é uma mulher virtuosa, devotada ao marido, que se vê forçada a uma ligação sexual com outro homem e que, para preservar seu respeito próprio e incapaz de suportar a vergonha da perda da honra, suicida-se com uma lâmina afiada. Pode-se até perguntar se o modelo de Lucrécia é responsável pelo que é frequentemente visto como um aspecto incomum da psicologia de Dido, sua dedicação resoluta à fidelidade para com o falecido marido. Isso extrapola o ideal da uniuira, a mulher que tem apenas um marido ao longo de toda a vida; esse ideal não contempla a expectativa de que uma viúva nunca se case novamente. Mas é uma maneira de introduzir na personagem de Dido uma dedicação absoluta ao um pudor inviolável equivalente ao de Lucrécia na relação com o marido vivo.

Tem sido incansavelmente debatida a relativa inocência e culpa de Dido e Eneias. Numa comparação, Lucrécia aparece como um modelo inalcançável, talvez antipático, de imaculada virtude. Mas na tradição posterior, há críticas a Lucrécia a partir de duas linhas de ataque: primeiro, a possibilidade de que ela possa ter cedido ao prazer sexual durante o estupro, e, segundo, se ela não o fez, a acusação é que ela estava encantada demais com sua própria boa reputação e fama ${ }^{18}$ Portanto, tem havido um debate a respeito da culpabilidade, ou algo assim, de Lucrécia tanto quanto prossegue o debate sobre a relativa culpabilidade de Dido e Eneias. É claro que não há dúvidas de que Dido, na versão de Virgílio, realmente quis manter relações sexuais com Eneias. Pode-se argumentar que um dos defeitos da Dido virgiliana é uma fixação excessiva em sua fama, uma falha que ela partilha

18 Donaldson 1982, cap. 2 ("The questioning of the myth"); ver também Allen 1968, 58-9, acerca do amor exagerado de Lucrécia pela glória. 
com o Ajax de Sófocles, uma peça à qual os livros Iv e vi da Eneida fazem uma série de alusões. Já existe talvez uma ponta de crítica nesse sentido no fraseado da narrativa de Ovídio quando Lucrécia finalmente cede a Sexto: "succubuit famae uicta puella metu" (Fast. 2.810). Como observa Matthew Robinson num comentário recente, até que alcancemos o final do pentâmetro, podemos considerar famae como dativo de succubuit ao invés de genitivo de metu: "ela se rendeu à (sua preocupação com) sua reputação". Succumbo, seguido do dativo, é a frase usada por Dido quando confessa a atração que tem por Eneias: "huic uni forsan potui succumbere culpae" (Aen. 4.19). A fama de Lucrécia é a sua culpa, seu calcanhar de Aquiles? Succumbo também pode ser usado acerca de uma mulher deitada sob um homem numa relação sexual: Lucrécia está encantada demais com sua fama?

Essas duas correntes da crítica a Dido são desenvolvidas sem piedade por Santo Agostinho como advogado de acusação em A Cidade de Deus 1.19. Agostinho instaura uma controversia a ser julgada segundo as leis e juízes de Roma: "Adultera haec an casta iudicanda est?" Se ela se matou sendo inocente, é culpada de homicidium; mas há também a possibilidade de "quamuis iuueni uiolenter irruenti etiam sua libidine illecta consensit", sendo, nesse caso, culpada de adulterium. Se não houve adultério (1.19):

non est ea pudicitiae caritas, sed pudoris infirmitas. puduit enim eam turpitudinis alienae in se commissae, etiamsi non secum, et Romana mulier, laudis auida nimium, uerita est ne putaretur, quod uiolenter est passa cum uiueret, libenter passa si uiueret.

Ao contrário, as feminae Christianae que sofreram o mesmo não se matam, "habent quippe intus gloriam castitatis, testimonium conscientiae. habent autem coram oculis Dei sui..."

Coluccio Salutati, humanista e chanceler de Florença, escreveu uma declamatio sobre a polêmica se Lucrécia deveria matar-se. No discurso inicial, o pai dela e o marido apresentam argumentos contrários e, num segundo discurso, Lucrécia apresenta os argumentos a favor..$^{19}$ Ela inicia com a indelével infamia que sofrerá se viver. Depois, confessa que não conseguiu evitar sentir algum prazer na violação. A polêmica é se Lucrécia poderia realmente ter desfrutado da experiência de ser violentada, culpada de sucumbir à concupiscentia. Salutati Declamatio Lucretiae, "Lucretiae responsio" (texto de Follak):

nec ab illo compressu mentem adeo reuocare [potui] quin subierint male obedientium membrorum illecebre, quin agnouerim uestigia maritalis flammae. illa, illa tristis et ingrata licet, qualiscumque tamen uoluptas ferro ulciscenda est...

\footnotetext{
${ }_{19}$ Klecker 2003, 432 (n.19), citando a partir de J. Follak, 2002, "Lucretia zwischen positiver und negativer Anthropologie. Coluccio Salutatis Declamatio Lucretie und die Menschenbilder im exemplum der Lucretia von der Antike bis in die Neuzeit." diss. Konstanz.
} 
Numa autorrecriminação, ela afirma que "nichil muliere mobilius..." (Klecker 2003, 432). Observe as alusões à Eneida de Virgílio: "agnosco ueteris uestigia flammae" (4.23); "uarium et mutabile semper / femina" (4.569-70). (Cf. as duas versões de Lucrécia em Lydgate: 1. Que ela gostou de ser violentada; 2. Que ela era totalmente inocente. ${ }^{20}$ )

A naturalidade do entrecruzamento das narrativas de Dido e de Lucrécia é atestada nas abordagens do tema de Lucrécia posteriores à Antiguidade. Uma série delas é destacada por Elisabeth Klecker em artigo de 2003. Já tratamos da "contaminação" da narrativa de Lucrécia por Petrarca com material da versão virgiliana de Dido e também passamos pela Declamatio Lucretiae de Coluccio Salutati, na qual Lucrécia revela sua angústia de que talvez fosse tão imune à tentação erótica quanto a Dido de Virgílio. Klecker também faz referência ao livro de sucesso de Enea Silvio Piccolomini Historia de duobus amantibus, Euríalo e Lucrécia, no qual a bela e casada Lucrécia, de Siena, considera por um momento superar a Lucrécia original "'Decretum est', ait Lucretia, 'mori. Admissum scelus Collatini uxor gladio uindicauit. Ego honestius praeueniam morte committendum" - antes que a trama enverede por uma repetição do enredo do livro IV da Eneida. ${ }^{21}$ Fama é um motivo central: Euríalo escreve para sua amada "nomen habes tum pulcerrime tum pudicissime mulieris" e faz um relato hiperbólico da fama dela: "nec apud Italos solum tua fama clauditur, sed et Teutones et Pannonnii et Bohemi et omnes septentrionis Populi tuum nomen agnoscunt". De início, a preocupação central de Lucrécia é com sua fama.

O principal exemplo de Klecker é o drama Lucretia, do escritor silesiano Samuel Iunius (1567-?), encenado em Estrasburgo em 1599. O texto de Lucretia se aproveita de textos anteriores, incluindo traduções latinas da Ifigênia em Áulis, de Eurípides (por Erasmo), e do Ajax, de Sófocles. O Ajax sofocleano se presta facilmente como modelo para a determinação de Lucrécia em evitar a vergonha por meio da morte assim como tinha sido para a Dido virgiliana a recusa em conviver com a perda da fama e do pudor: são bem conhecidas as alusões ao Ajax de Sófocles no livro Iv da Eneida.22 Dessa forma, Lucrécia reafirma sua determinação em morrer antes de transgredir iura uerecundiae, numa adaptação próxima $(\mathrm{C} 2 \mathrm{v})$ à suplica de Dido de que fosse tragada pela terra ou fulminada por um raio na Eneida 4.24-7. Ela morre com as ipsissima uerba da Dido moribunda (Giv): "sic sic iuuat/ire sub umbras"

${ }^{20}$ De acordo com Schmitz 1990, 76-104 ("The matron of Rome: Lucrece in medieval and Renaissance poetry"), e 77-8 sobre ambas versões.

${ }^{21}$ Klecker 2003, 432-3, referindo-se a Leube 1969, 165-72.

22 Ver esp. Tatum 1984, 446-51, sobre o paralelo entre a identificação de Ajax com sua timé e o desespero de Dido com a perda de seu pudor e de sua fama. 
(Verg. A. 4.66o). O coro das mulheres romanas na Lucretia de Iunius clama por um vingador de Lucrécia usando as palavras de Dido à morte (C1v): "exorere nostra tandem stirpe quispiam" (cf. Verg. A. 4.625: "exoriare aliquis nostris ex ossibus ultor"). Como faz Ovídio na história de Lucrécia no livro II dos Fasti, a linguagem do mal de amor de Dido é deslocada para Sexto (D2v): "Ah enecor, quoties imago animum haec subit; usque adeo inhaerent fixi uultus pectore" (cf. Verg. A. 4.3-4: "multa uiri uirtus animo multusque recursat / gentis honos; haerent infixi pectore uultus"); (D7v): "postquam amor meis inhaesit ossibus / totasque medullas est populans crudeliter" (cf. Verg. A. 4.66: "est mollis flama medullas").

A morte da Dido de Virgílio desencadeia uma série de acontecimentos que vai se encerrar na destruição de Cartago em 146 a.C. como uma repetição da queda de Troia. A empatia de Dido com o sofrimento dos troianos, ironicamente, alimenta seu amor por Eneias, uma vítima inocente da destruição imposta pelos gregos à sua cidade que vai acabar provocando a morte de Dido e, por isso, futuramente, a tomada da cidade dela, exatamente como a queda de Troia foi possível pelo ardil de Sínon ao conquistar a confiança e a amizade dos troianos. No livro II dos Fasti, Sexto Tarquínio desempenha o papel do Sínon virgiliano quando conquista ardilosamente a confiança dos cidadãos de Gábios, e é com falsidade e ardil que consegue ser recebido por Lucrécia e a violenta. O comentador renascentista Paulo Marso, comentando o livro II dos Fasti, observou o paralelo entre Sexto na cidade de Gábios e Sínon no livro II da Eneida, assim como já se disse que foi o comentário de Marsus que motivou Shakespeare a incluir uma longa comparação de Sínon com o estuprador Sexto em The Rape of Lucrece (1594).23 (Embora se possa questionar se Shakespeare não teria sido capaz de fazer a relação direta a partir de suas leituras de Virgílio e Ovídio.) Esse é o clímax na écfrase de uma pintura do cerco de Troia que Lucrécia observa enquanto espera a volta do marido à casa em função de uma mensageiro que ela enviara (vv. 1366-1568). Para Lucrécia, a pintura é um "means to mourn some newer way" (v. 1365), e vê nela várias semelhanças com sua própria situação e estado de espírito, num exemplo extremado do que pode ser chamado de "identificação ecfrástica" de mão dupla (v. 1498: "She lends them words, and she their looks does borrow"). Esta não é a primeira vez que ela buscou, nas lendas, analogias com a própria experiência; antes, tinha invocado Filomela, o rouxinol, para se unir a ela num dueto acerca de seus males em comum: "For burden-wise I'll hum on Tarquin still, While thou on Tereus descants better skill" (vv. 1333-4). ${ }^{24}$

${ }_{23}$ Bate 1993, 79-80, com base em Baldwin 1950, 145, retomado por Burrow 2002, 48-9.

${ }^{24}$ Ver Bate 1993, 75-7, sugerindo também que a tentativa final de Lucrécia de dar nome ao seu estuprador repete o "grito abafado, meio inarticulado" de Filomela: "Tereu, Tereu". Esse é o 
A écfrase do cerco de Troia em Shakespeare nos remete ao início da visita de Eneias a Cartago, no livro I da Eneida, e às cenas da guerra de Troia que ele vê no Templo de Juno, cenas com múltiplas ressonâncias não apenas da própria vivência passada de Eneias, mas da história futura de Cartago e de Roma. ${ }^{25}$ Na pintura que Lucrécia admira, está estampado "o poder da Grécia" diante da Troia de Príamo: "For Helen's rape the city to destroy" (v. 1369). Jonathan Bate afirma: "O rapto de Helena levou à queda de Troia; o rapto de Lucrécia leva ao surgimento da República romana." ${ }^{26}$ Ironicamente, Lucrécia não tem como saber que seu estupro terá uma consequência marcante para a sua cidade de Roma. Ao emprestar a voz, apaixonadamente, à silente imagem de Hécuba na pintura, ${ }^{27}$ quando ela "shapes her sorrow to the beldam's woes" (v. 1459), protesta contra "the strumpet [Helen] that began this stir" (v. 1471), mas devota muitas linhas mais a atacar a luxúria de Páris, misturando suas palavras com o ódio contra o estuprador Tarquínio: "Had doting Priam checked his son's desire / Troy had been bright with fame, and not with fire" (vv. 1491-2). Sua fama e vergonha são uma obsessão dessa Lucrécia durante todo o poema. ${ }^{28}$ Mas é em Sínon que ela encontra um correlativo mais exato com Tarquínio (vv. 1499-1568). Sínon é o dissimulado "Whose words like wild-fire burnt the shining glory / Of rich-built Ilium" (vv. 1524-5). A habilidade do pintor se manifesta numa figura que parece tão sincera e confiável que apenas a partir de sua própria experiência é que Lucrécia é capaz de acreditar "that so much guile... can lurk in such a look" (vv. 1534-5). Fazendo uma analogia entre a experiência de Troia e a dela própria, conclui "as Priam him did cherish / So did I Tarquin; so my Troy did perish" (vv. 1546-7). Burrow $(2002,315)$ observa acerca dos versos 1366 a 1568 que a écfrase "leva a um clímax as imagens do cerco e da batalha que percorreram o poema até aqui", a simetria do corpo da mulher com a cidade murada que constitui tanto a história de Lucrécia em Ovídio como a de Dido em Virgílio.

último exemplo do tratamento que Shakespeare dá ao tema do silêncio e da fala, central às narrativas ovidianas sobre Lucrécia e Filomela.

${ }_{25}$ Ver preferencialmente Barchiesi 1999.

${ }^{26}$ Bate 1993, 81. Helena como um análogo de Lucrécia: laços entre Helena e a Dido de Virgílio nas Heroides 16-17 de Ovídio. Hans Sachs, Tragedia. Von der Lucretia (1527): Tarquínio comparado a Páris, levando Helena embora para Troia (Donaldson 1982).

${ }^{27}$ Lucrécia dá a Hécuba a liberdade de falar que o pintor, com toda sua habilidade, não lhe pode dar: "And therefore Lucrece swears he did her wrong, / To give her so much grief, and not a tongue. // Poor instrument", quoth she, "without a sound, / I'll tune my woes with my lamenting tongue" (vv.1462-5). Shakespeare reage ao tema da fala e do silêncio nas histórias de Ovídio sobre Lucrécia e Filomela.

${ }_{28}$ Ver Dubrow 1986, 404-7, sobre as consequências morais e emocionais de um interesse grande demais pela fama. 
A écfrase de uma pintura da guerra de Troia alude às cenas do Templo de Juno no livro i da Eneida. A história de Sínon é retirada do livro II da Eneida. Considerando os modelos de Virgílio, Lucrécia é tanto Eneias, reagindo emocionalmente às imagens da guerra que ele viveu pessoalmente, como Dido, reagindo emocionalmente à narrativa carregada de pathos do forasteiro cujas vivências se cruzam em alguns pontos com as dela própria. A combinação em Shakespeare da écfrase virgiliana com a narrativa de Eneias reflete o paralelismo na Eneida dessas duas representações incrustadas de Troia, uma visual e uma verbal. Eneias e Dido, ambos, identificam-se fortemente com o que veem e ouvem, ambos estão conscientes de parte do significado para eles mesmos daquilo que veem ou ouvem, mas não de tudo, e o mesmo pode ser dito de Lucrécia e de sua reação à pintura de Troia.

Não me parece que Shakespeare tenha bebido preferencialmente na fonte da Dido de Virgílio para fazer seu retrato de Lucrécia. Tal qual Venus and Adonis, publicado no ano anterior, em 1593, The Rape of Lucrece é uma produção mais ovidiana do que virgiliana, surgida no modismo da epyllia ovididana da poesia inglesa dos anos 1590. A Eneida está presente enfaticamente no recurso a uma écfrase de cenas da guerra de Troia, baseada fundamentalmente no livro I, e na história de Sínon, do livro ir. O recurso à guerra de Troia como um modelo ou analogia para outras histórias, de caráter público ou privado, é central na estratégia narrativa de Virgílio na Eneida como um todo, e não o é menos na construção virgiliana da história de Dido nos livros I e IV. A configuração das linhas gerais de uma narrativa com base em outra e a adaptação da história de um personagem lendário ou mitológico à história de outro constituem um expediente importante para a construção de sentido na Eneida, e nessa habilidade Ovídio concorre com Virgílio: Lucrécia no livro II dos Fasti e Filomela no livro vi das Metamorfoses são bons exemplos disso e, de forma alguma, incomuns. A força de suas emoções dá à Lucrécia de Shakespeare o poder de ver sua própria história escrita ou pintada nas histórias de outros - Filomela, Helena e Páris, Hécuba e Sínon. Esse poder, particularmente no contexto do ciclo de narrativas de Troia e Roma, é, em parte, um poder virgiliano, que se manifesta, como argumentei, numa extensa rede de correspondências e contrastes significativos que ligam a Dido de Virgílio a Lucrécia. ${ }^{29}$

\footnotetext{
29 Email do autor: prh1004@cam.ac.uk

Tradução: Renata Cazarini de Freitas
} 


\section{REFERÊNCIAS}

Allen, Don Cameron. 1968. "William Shakespeare, 'The Rape of Lucrece'." Image and Meaning, Metaphoric Tradition in Renaissance Poetry. Baltimore, MD: Johns Hopkins Press.

Baldwin, Thomas Whitfield. 1950. On the Literary Genetics of Shakspere's Poems and Sonnets. Urbana, ILL.: University of Illinois Press.

Barchiesi, A. 1999. "Representations of suffering and interpretation in the Aeneid." In Virgil: Critical Assessments of Classical Authors vol. III, ed. Philip Hardie, 324-44. London-New York: Routledge. [Trad. de A. Barchiesi, 1994, "Rappresentazioni del dolore e interpretazione nell'Eneide," Antike und Abendland 40: 109-24.]

Bate, Jonathan. 1993. Shakespeare and Ovid. Oxford: Clarendon Paperbacks.

Burrow, Colin, ed. 2002. The Oxford Shakespeare: The Complete Sonnets and Poems. Oxford: OUP.

Donaldson, Ian. 1982. The rapes of Lucretia. Oxford: Clarendon Press.

Dubrow, H. 1986. "A mirror for complaints: Shakespeare's Lucrece and generic tradition." In Renaissance Genre: Essays on Theory, History, and Interpretation, ed. Barbara Kiefer Lewalski, 399-417. Cambridge, MA-London: Harvard University Press.

Edwards, Catherine. 2007. Death in Ancient Rome. New Haven-London: Yale University Press.

Feldherr, Andrew. 1998. Spectacle and Society in Livy's History. Berkeley-Los AngelesLondon: University of California Press.

Felton, D. 1998. "Advice to tyrants: the motif of 'enigmatic counsel' in Greek and Roman texts." Phoenix 52(1): 42-54.

Hardie, Philip, ed. 1999. Virgil: Critical Assessments of Classical Authors, vol. III. Londres e Nova York: Routledge.

Jed, Stephanie H. 1989. Chaste Thinking, The Rape of Lucretia and the Birth of Humanism. Bloomington-Indianapolis: Indiana University Press.

Joplin, P. K. 1990. Ritual work on human flesh: Livy's Lucretia and the rape of the body politic. Helios 17(1): 51-70.

Joshel, S. R. 2009. "The body female and the body politic: Livy's Lucretia and Verginia." In Oxford Readings in Classical Studies: Livy, eds. Jane D. Chaplin; Cristina S. Kraus, 380-408. Oxford: OUP. [Publ. orig. in Pornography and Representation in Greece and Rome, ed. A. Richlin, 1992, 112-30. Oxford.]

Klecker, Elisabeth. 2003. "Zur Präsentation römischer Geschichte in der neulateinischen Dichtung. Vergilrezeption im Lucretiadrama des Samuel Iunius (Straßburg 1599)." AAntHung 43: 423-38.

Langlands, Rebecca. 2006. Sexual morality in Ancient Rome. Cambridge: Cambridge University Press.

Leube, Eberhard. 1969. Fortuna in Karthago: Die Aeneas-Dido-Mythe in den romanischen Literaturen vom 14. bis zum 16. Jahrhundert. Heidelberg: Carl Winter Universitatsverlag.

Lewalski, Barbara Kiefer, ed. 1986. Renaissance Genre: Essays on Theory, History, and Interpretation. Cambridge, MA-London: Harvard University Press.

Lord, M. L. 1969. "Dido as an example of chastity: the influence of example literature." Harvard Library Bulletin 17: 22-44. 
Lydgate, John. 1924-27. Fall of princes, ed. Henry Bergen. London: OUP. 4 v.

Lyne, R. O. A. M. 1987. Further Voices in Vergil's Aeneid. Oxford: OUP.

Moorton, Richard F. 1990. "Love as death: the pivoting metaphor in Vergil's story of Dido." The Classical World 83: 153-66.

Nelis, Damien. 2001. Vergil's Aeneid and the Argonautica of Apollonius Rhodius. Leeds: Francis Cairns.

Phillipides, S. N. 1983. "Narrative strategies and ideology in Livy's 'Rape of Lucretia'." Helios 10: 113-19.

Robinson, Matthew. 2011. A commentary on Ovid's Fasti Book 2. Oxford: OUP.

Schmitz, Götz. 1990. The Fall of Women in Early English Narrative Verse. Cambridge: Cambridge University Press.

Tatum, J. 1984. "Allusion and interpretation in Aeneid 6.440-76." American Journal of Philology 105: 434-52.

Abstract. In this paper I explore the links between the Virgilian version of Dido, the woman whose fall from chastity leads to her suicide, and, through her dying curse, eventually to the destruction of her city of Carthage in the Punic Wars, and Lucretia, the woman whose suicide as vindication of her innocence after her rape is a foundational event in the history of the city of Rome, leading to the expulsion of the kings and the establishment of the republic. A detailed study of the Virgilian narrative, in which I argue that the shadow of Lucretia hovers behind the figure of Dido, is followed by a sampling of the later history of the association of Dido and Lucretia, from the Church Fathers to Shakespeare.

Keywords. Virgil, Ovid, Shakespeare, Lucretia, Dido. 